\title{
Case Report \\ Occult Papillary Thyroid Carcinoma Metastasis to the Sacrum and the Skull: An Unusual Presentation
}

\author{
Fatima S. Jouhar, Asif Quadri, Bachar Afandi, and Sadir Al Rawi \\ Department of Surgery, Division of Surgical Oncology, Tawam Hospital, Al Ain, Abu Dhabi, UAE \\ Correspondence should be addressed to Fatima S. Jouhar; jouharf@gmail.com
}

Received 4 August 2014; Revised 26 October 2014; Accepted 9 November 2014; Published 8 December 2014

Academic Editor: Aaron S. Dumont

Copyright ( 2014 Fatima S. Jouhar et al. This is an open access article distributed under the Creative Commons Attribution License, which permits unrestricted use, distribution, and reproduction in any medium, provided the original work is properly cited.

\begin{abstract}
This case represents occult follicular variant of papillary thyroid carcinoma (FVPTC) with large metastasis to the sacrum. The patient, a 42-year-old female, presented after hemithyroidectomy for benign follicular adenoma with lower back pain associated with fever and sweating. A lytic lesion of the left sacral bone was found on the CT with biopsy showing metastatic carcinoma with morphology and immunophenotype of thyroid gland primary tumor proven to be FVPTC. The patient had completion thyroidectomy with benign pathology.
\end{abstract}

\section{Introduction}

Occult presentation of primary thyroid malignancy can be defined by the McGraw-Hill Concise Dictionary of Modern Medicine (2002) as "Unknown primary malignancy that is symptomless, which first manifest itself as metastasis or secondary-para-neoplastic phenomena" [1]. It can be classified into four categories: (1) thyroid carcinoma or microcarcinoma as an incidental finding after total thyroidectomy for benign mass, (2) radiological incidental finding of thyroid carcinoma with positive FNA result, (3) apparent thyroid metastasis with primary tumor unidentified prior to final histological specimen, and (4) symptomatic ectopic thyroid tissue with apparent metastasis [1]. In this case the patient presented with an apparent metastasis with pathology showing benign follicular adenoma.

\section{Case Report}

A 42-year-old female presented with right neck swelling which was initially diagnosed as follicular adenoma. Patient underwent a right hemithyroidectomy and isthmus resection and was maintained on levothyroxine. Nine years later she presented with lower back pain associated with fever and sweating. CT scan of abdomen and pelvis showed lytic lesion of the sacrum. Three-phase bone scintigraphy showed substantial perfusion to the soft tissue mass located in left side of sacrum with photogenic area in the left sacroiliac joint region, surrounded medially with actively metabolic bony lesion. Sacral biopsy showed metastatic carcinoma with morphology and immunophenotype suggestive of thyroid gland primary tumor (positive thyroglobulin) and positive CK7+/CK20 - (Figure 2). Positron emission tomography (PET)/CT scan showed large destructive left sacral lesion of $6.2 \times 3.5 \times 8.6 \mathrm{~cm}$ in size with soft tissue component involving S1, S2, and S3 vertebra, extending to the neural foramina of the involved vertebra and L5 vertebra, as well with very intense hypermetabolism (Figure 1). Patient was having decreased sense of vibration on her left lower limb. Patient was referred to the oncology center for palliative radiotherapy and completed 13 cycles. Patient was found to have left lobe thyroid nodule of $0.43 \times 0.87 \times 0.8 \mathrm{~cm}$; FNA showed benign follicular hyperplastic nodule. Thyroglobulin level was elevated up to $>600.0$. Patient had completion thyroidectomy and lymph nodes dissection. Histopathology showed benign nodular hyperplasia of thyroid with negative lymph nodes. Iodine 131 uptake scan showed minimal uptake in thyroid bed, high uptake in pelvic region on the sacral mass, and hot round area in the posterior parietal region of the skull. 


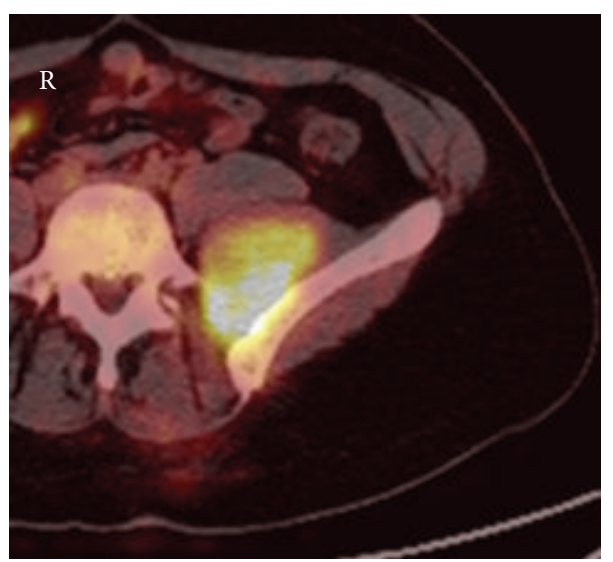

(a)

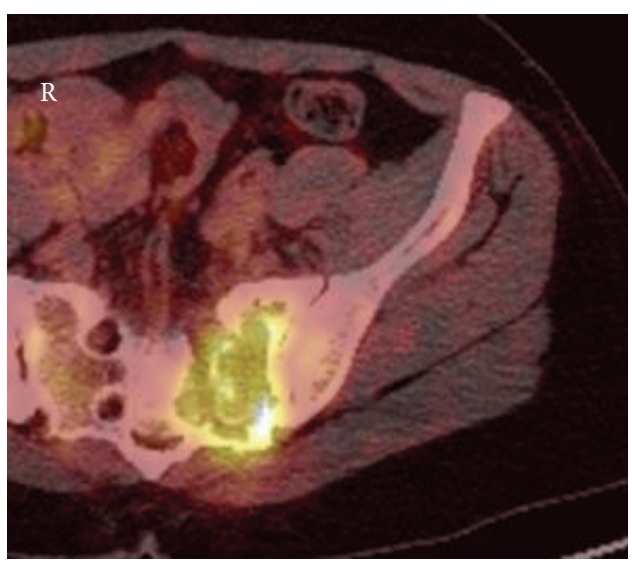

(b)

FIGURE 1: PET CT left osteolytic sacral lesion of $6.2 \times 3.5 \times 8.6 \mathrm{~cm} \mathrm{S1}$, S2, and S3 vertebral involvement extending to the neural foramina with very intense hypermetabolism.

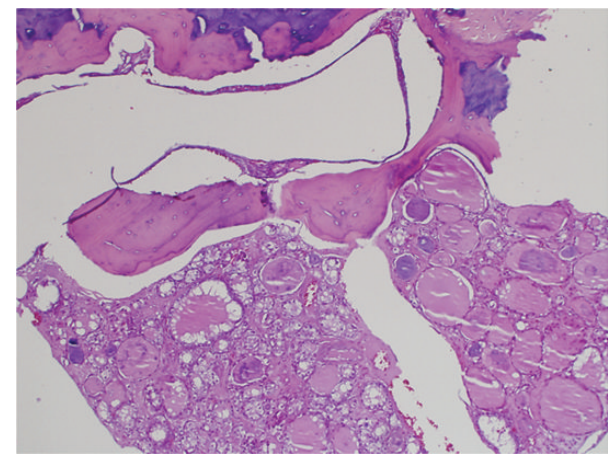

FIGURE 2: HE $\times 4$ showing tumor invading bone.

\section{Discussion}

This patient was found to have sacral mass which was diagnosed as an invasive tumor of thyroid origin. This was proven via the characteristic of the tumor with (1) bone invasion (Figure 2), (2) follicles filled with colloid, and (3) positive thyroglobulin and CK7+/CK20-. This current histopathology finding could be presented in papillary thyroid carcinoma, follicular thyroid carcinoma, and FVPTC, but the histopathology result was more suggestive of FVPTC which is represented in the higher magnification micrograph showing optical clear, overlapping, and grooved nuclei. This is highly suggestive of the papillary characteristics [2] (Figures 3(a) and $3(\mathrm{~b}))$.

FVPTC has follicular architectural pattern with nuclear features of PTC. FVPTC can be misdiagnosed as follicular adenoma or follicular thyroid carcinoma in the presence of capsular or vascular invasion. It can present in larger size and in younger age groups. Although it is believed that FVPTC has similar prognosis of PTC, it can mimic the features of follicular neoplasm in terms of distal metastasis with absence of lymph node involvement and prevalence of vascular and capsular invasion. In spite of that, recent studies show FVPTC has favorable clinic pathological features compared to PTC, but similar long-term outcomes [3].

In this case the primary tumor was not found since both histopathology reports for the thyroid tissue in 2003 and 2013 revealed benign follicular adenoma. The absence of the primary tumor in this case can be either due to regression of tumor at the primary site with distant bone metastasis or due to a small primary tumor that could not be detected despite thorough examination [4].

It is believed that $1 \%-3 \%$ of thyroid cancer can develop distant metastasis. Occult clinical presentation delays the diagnosis and management of metastasis [5]. After the fourth decade $10 \%$ of patients with papillary thyroid cancer develop distant metastasis [6]. Metastases outside the neck and mediastinum are considered in $11 \%$ of patients with papillary thyroid carcinoma [5]. 2-13\% of patients with well-differentiated thyroid cancer develop bone metastasis [7]. Bone is the second most commonly involved site after the lungs [6]. Compared to follicular thyroid carcinoma $28-97 \%$ papillary thyroid cancer has $1.4-7 \%$ of bone metastasis [7].

There have been cases in the literature reported in papillary thyroid metastasizing to the bone at different metastatic sites (Table 1). Bone metastasis increases mortality rate, decreases the quality of life, and shortens the patients' survival [8]. The presence of metachronous bone metastasis alone is a significant indicator of poor prognosis [9]. Large invasive bone metastases can be managed with aggressive surgical approach. Nevertheless, not all bone lesions are amenable to surgical excision [10].

Giving this case as an example, surgical excision in her condition will affect mobilization in addition to the neurological function due to the extensive invasionue to the extensive invasiveness to the bone and the involvement of the nerve roots at the level of the tumor. Alternative treatment such as arterial embolization or percutaneous radiofrequency ablation can be offered in her case [10]. Patient's case was discussed in the tumor multidisciplinary meeting and conservative palliative management was decided for the patient as surgery's risk exceeded the benefit in this case. 
TABLE 1: Cases of occult and overt papillary thyroid carcinoma metastasis to the bone indicating different metastatic sites.

\begin{tabular}{|c|c|c|c|c|c|c|}
\hline & Author & Age in years & Gender & Type & Metastatic site & Year \\
\hline 1 & Sziklas et al. [11] & 44 & Male & Overt & Skull/ribs/pelvis & 1985 \\
\hline 2 & Nishikawa et al. [4] & 51 & Male & Occult & Ribs & 1998 \\
\hline 3 & Hashiba et al. [12] & 74 & Female & Overt & Skull & 2006 \\
\hline 4 & Slim et al. [13] & 67 & Female & Overt & Malar bone & 2012 \\
\hline 5 & Cardenas et al. [14] & 59 & Female & Overt & Skull/ribs/pelvis & 2009 \\
\hline 6 & Cardenas et al. [14] & 81 & Male & Overt & Shoulder & 2009 \\
\hline 7 & Chakravarthy et al. [15] & 32 & Female & Overt & Metacarpal bone & 2010 \\
\hline 8 & Siddiq et al. [16] & 59 & Female & Overt & Iliac bone & 2010 \\
\hline 9 & Özuğuz et al. [6] & 35 & Female & Overt & Ischium pubis & 2011 \\
\hline 10 & Hugh et al. [17] & 64 & Female & Overt & Temporal bone & 2011 \\
\hline 11 & Luna-Ortiz et al. [18] & 30 & Female & Overt & Sternum & 2013 \\
\hline 12 & Nigam et al. [19] & 48 & Female & Overt & Skull & 2012 \\
\hline 13 & Stojanie et al. [20] & 56 & Male & Overt & Sacrum & 2012 \\
\hline 14 & Kutluhan et al. [21] & 61 & Male & Overt & Skull & 2012 \\
\hline 15 & Luna-Ortiz et al. [18] & 74 & Female & Overt & Sternum/ribs & 2013 \\
\hline 16 & Del Rio et al. [22] & 60 & Female & Overt & Pelvis & 2013 \\
\hline 17 & Godbert et al. [23] & 65 & Male & Overt & Ribs & 2013 \\
\hline 18 & Sachmechi et al. [24] & 44 & Female & Overt & Skull & 2014 \\
\hline
\end{tabular}

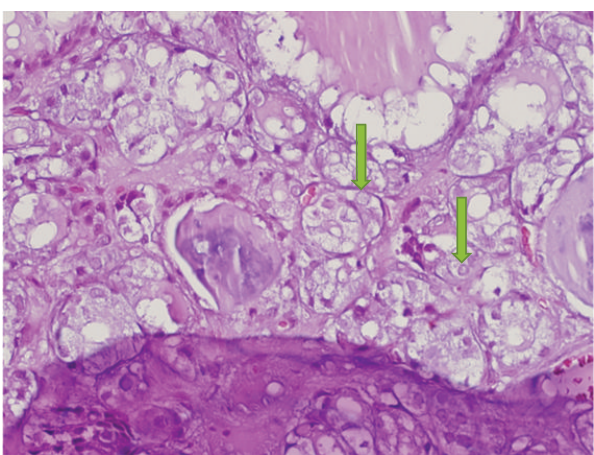

(a)

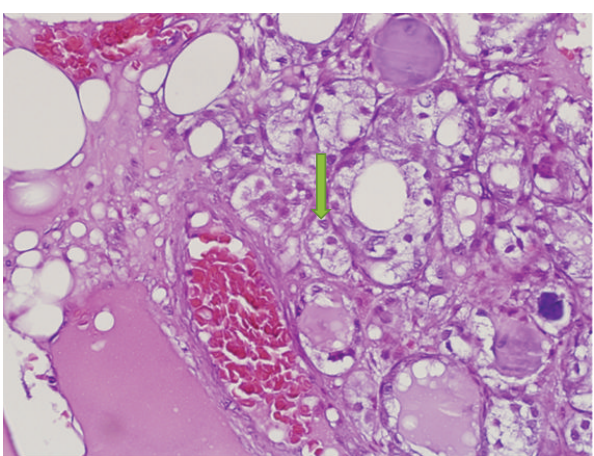

(b)

Figure 3: (a) HE $\times 20$-nuclear overlapping is obvious in the lining tumor cells. (b) HE $\times 40$-nuclear clearing in some nuclei (arrows).

\section{Conclusion}

This case illustrates a rare presentation of metastatic lesion to the sacrum and the skull of histopathology highly suggestive of FVPTC. In addition to the rare finding of absence of primary lesion the histopathology result of the thyroidectomy showed benign follicular adenoma. Metastasis to the bone is considered more common in follicular thyroid carcinoma compared to papillary thyroid carcinoma which tends to increase the morbidity and mortality. Although FVPTC can mimic follicular thyroid cancer, it has similar prognosis to papillary thyroid carcinoma. Not all bone metastases can be managed surgically depending on the location and the postoperative outcome. Alternative treatment should be considered to improve patient morbidity.

\section{Conflict of Interests}

The authors have no conflict of interests to declare.

\section{Acknowledgment}

The authors would like to thank Dr. Michael Jansen, Consultant Histopathologist and Neuropathologist, at the Department of Pathology and Genetics in Dubai Hospital, for his contribution to the case.

\section{References}

[1] J. Boucek, J. Kastner, J. Skrivan et al., "Occult thyroid carcinoma," Acta Otorhinolaryngologica Italica, vol. 29, no. 6, pp. 296-304, 2009.

[2] C. D. Scopa, "Histopathology of thyroid tumors. An overview," Hormones, vol. 3, no. 2, pp. 100-110, 2004.

[3] A. Salajegheh, E. B. Petcu, R. A. Smith, and A. K.-Y. Lam, "Follicular variant of papillary thyroid carcinoma: a diagnostic challenge for clinicians and pathologists," Postgraduate Medical Journal, vol. 84, pp. 78-82, 2008, http://pmj.bmj.com/cgi/content/full/84/988/78. 
[4] M. Nishikawa, N. Toyoda, T. Yonemoto et al., "Occult papillary thyroid carcinoma in Hashimoto's thyroiditis presenting as a metastatic bone tumor," Endocrine Journal, vol. 45, no. 1, pp. 111116, 1998.

[5] L. Santacroce, "Papillary Thyroid Carcinoma," 2012, http://emedicine.medscape.com/article/282276-overview.

[6] U. Özuğuz, S. Işk, F. Gökay et al., "Unusual clinical course of papillary thyroid microcarcinoma: metastases of bone and lung," Turkish Journal of Endocrinology and Metabolism, vol. 15, no. 1, pp. 20-22, 2011.

[7] M. M. Muresan, P. Olivier, J. Leclère et al., "Bone metastases from differentiated thyroid carcinoma," Endocrine-Related Cancer, vol. 15, no. 1, pp. 37-49, 2008.

[8] K. Wu, S. Hou, T. Huang, and R. Yang, "Thyroid carcinoma with bone metastases: a prognostic factor study," Clinical Medicine: Oncology, vol. 2, pp. 129-134, 2008.

[9] Y. Orita, I. Sugitani, M. Matsuura et al., "Prognostic factors and the therapeutic strategy for patients with bone metastasis from differentiated thyroid carcinoma," Surgery, vol. 147, no. 3, pp. 424-431, 2010.

[10] P. Zanotti-Fregonara, D. Rubello, and E. Hindié, "Bone metastases of differentiated thyroid cancer: the importance of early diagnosis and ${ }^{131}$ I therapy on prognosis," The Journal of Nuclear Medicine, vol. 49, no. 11, pp. 1902-1903, 2008.

[11] J. J. Sziklas, J. Mathews, R. P. Spencer, R. J. Rosenberg, M. T. Ergin, and B. F. Bower, "Thyroid carcinoma metastatic to pituitary," The Journal of Nuclear Medicine, vol. 26, no. 9, p. 1097, 1985.

[12] T. Hashiba, M. Maruno, Y. Fujimoto et al., "Skull metastasis from papillary thyroid carcinoma accompanied by neurofibromatosis type 1 and pheochromocytoma: report of a case," Brain Tumor Pathology, vol. 23, no. 2, pp. 97-100, 2006.

[13] I. Slim, A. Mhiri, I. Meddeb, A. Goucha, S. Gritli, and M. F. Ben Slimene, "Malar bone metastasis revealing a papillary thyroid carcinoma," Case Reports in Otolaryngology, vol. 2012, Article ID 795686, 4 pages, 2012.

[14] M. G. Cardenas, S. Kini, and M. Wisgerhof, "Two cases of sternectomy for bone metastasis due to aggressive variants of thyroid papillary carcinoma," Thyroid, vol. 19, no. 4, pp. 413-416, 2009.

[15] V. K. Chakravarthy, N. D. Chandra Rao, and S. T. Chandra, "Study of papillary carcinoma of thyroid with uncommon sites of metastasis," Indian Journal of Otolaryngology and Head \& Neck Surgery, vol. 62, no. 2, pp. 198-201, 2010.

[16] S. Siddiq, I. Ahmad, and P. Colloby, "Papillary thyroid carcinoma presenting as an asymptomatic pelvic bone metastases," Journal of Surgical Case Reports, vol. 3, article 2, 2010, http://jscr.oxfordjournals.org/content/2010/3/2.full.pdf.

[17] S. C. Hugh, D. Enepekides, J. Wong, R. Yeung, and V. Y. W. Lin, "Metastasis of follicular variant of papillary thyroid carcinoma masquerading as primary temporal bone tumour," The Journal of Laryngology and Otology, vol. 125, no. 5, pp. 528-532, 2011.

[18] K. Luna-Ortiz, R. A. Salcedo-Hernández, L. S. Lino-Silvaemail, and A. Gómez-Pedraza, "Two cases of sternectomy for bone metastasis due to aggressive variants of thyroid papillary carcinoma," International Journal of Surgery Case Reports, vol. 4, no. 2, pp. 156-159, 2013.

[19] A. Nigam, A. K. Singh, S. K. Singh, and N. Singh, "Skull metastasis in papillary carcinoma of thyroid: a case report," Journal of Radiology, vol. 4, no. 6, pp. 286-290, 2012.
[20] R. M. Stojanie, V. Zivaljevie, A. Diklic et al., “The solitary bone metastasis as a first sign of papillary thyroid cancer," Acta Endocrinologica, vol. 8, no. 2, pp. 289-294, 2012.

[21] A. Kutluhan, G. Yalçıner, K. Bozdemir, E. Ozdemir, B. Tarlak, and A. S. Bilgen, "Papillary thyroid carcinoma with metastasis to the temporooccipital skull: a case report," Kulak Burun Boğaz Ihtisas Dergisi, vol. 22, no. 3, pp. 160-163, 2012.

[22] P. Del Rio, B. De Simone, G. Robuschi, and M. Sianesi, "Pelvic pain and papillary thyroid carcinoma. Case report," Annali Italiani di Chirurgia, vol. 84, no. 3, pp. 347-350, 2013.

[23] Y. Godbert, B. Henriques-Figueiredo, A.-L. Cazeau et al., "A papillary thyroid microcarcinoma revealed by a single bone lesion with no poor prognostic factors," Case Reports in Endocrinology, vol. 2013, Article ID 719304, 4 pages, 2013.

[24] I. Sachmechi, R. N. Bitton, S. Sanelli-Russo, and S. Thongpooswan, "An aggressive follicular variant of papillary thyroid carcinoma with unusual metastases-a case report and review of literature," British Journal of Medical Practitioners, vol. 7, no. 1, pp. 25-28, 2014. 


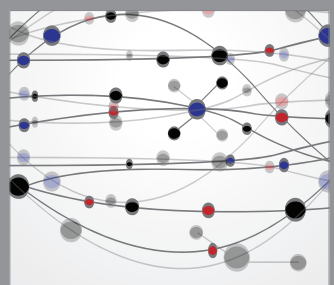

The Scientific World Journal
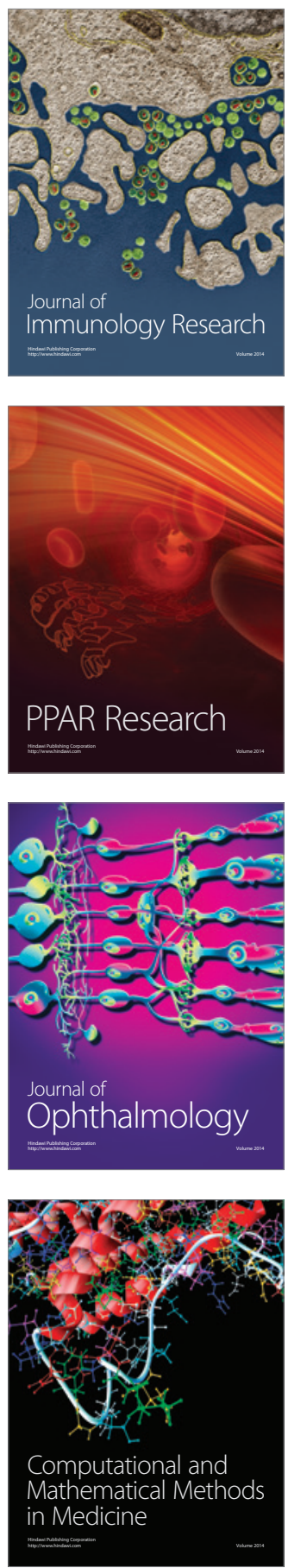

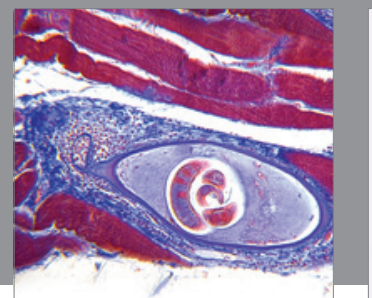

Gastroenterology

Research and Practice
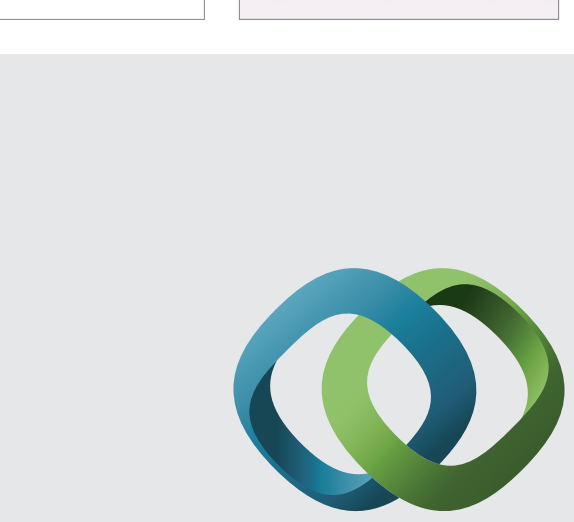

\section{Hindawi}

Submit your manuscripts at

http://www.hindawi.com
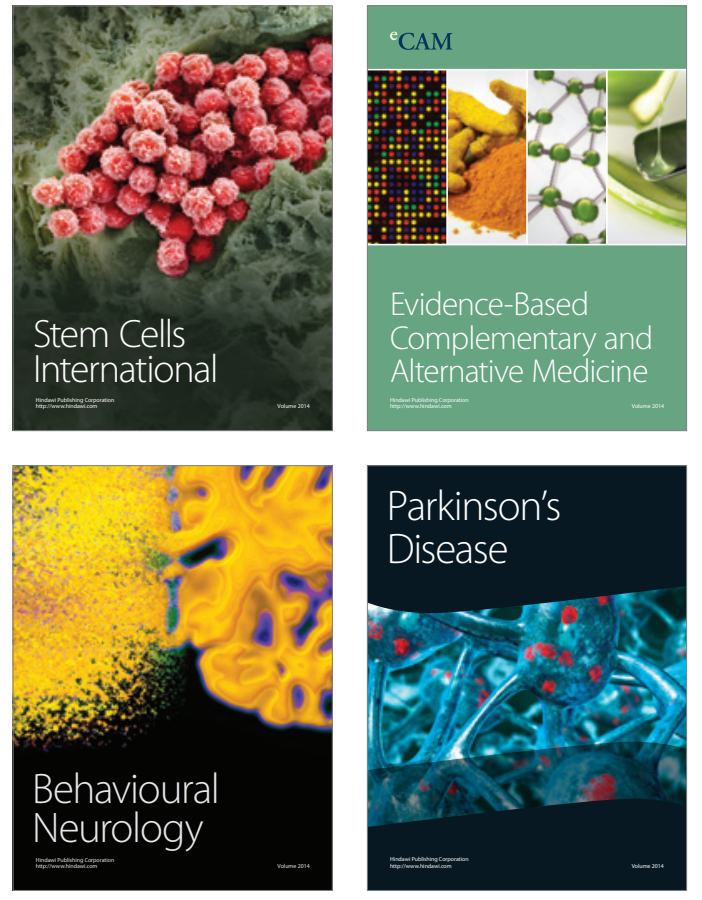
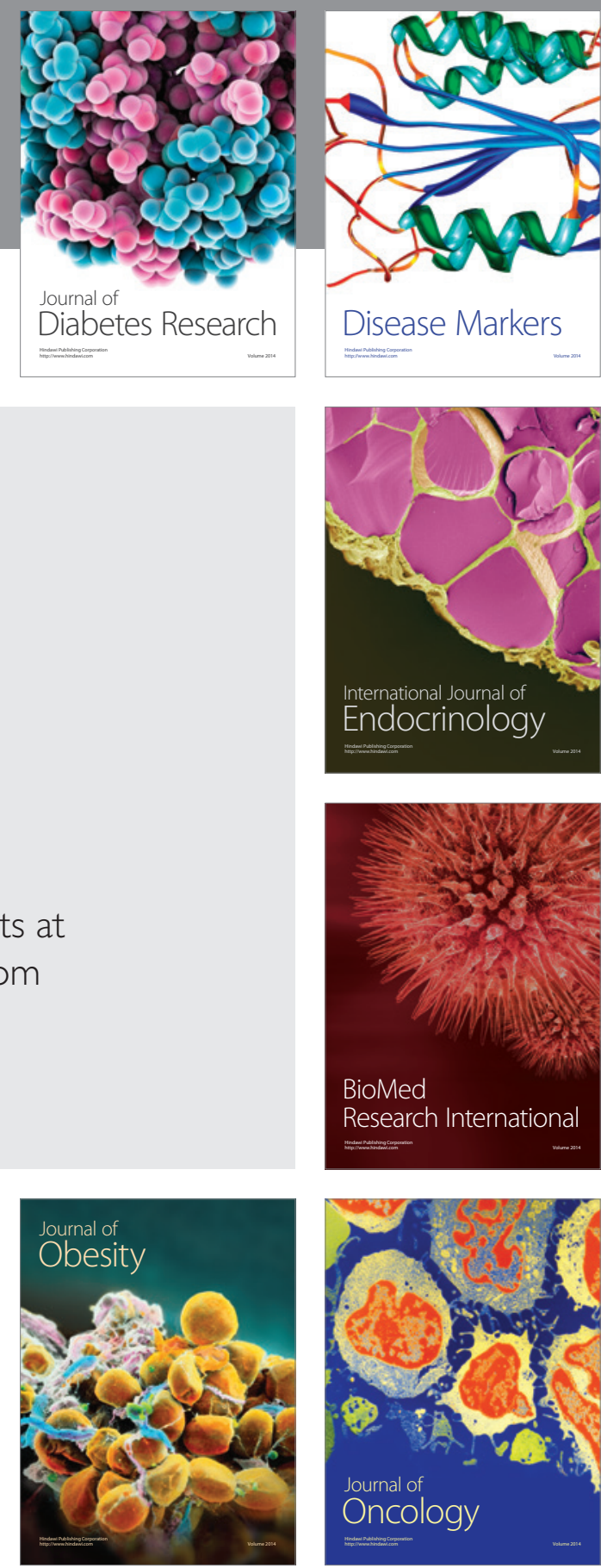

Disease Markers
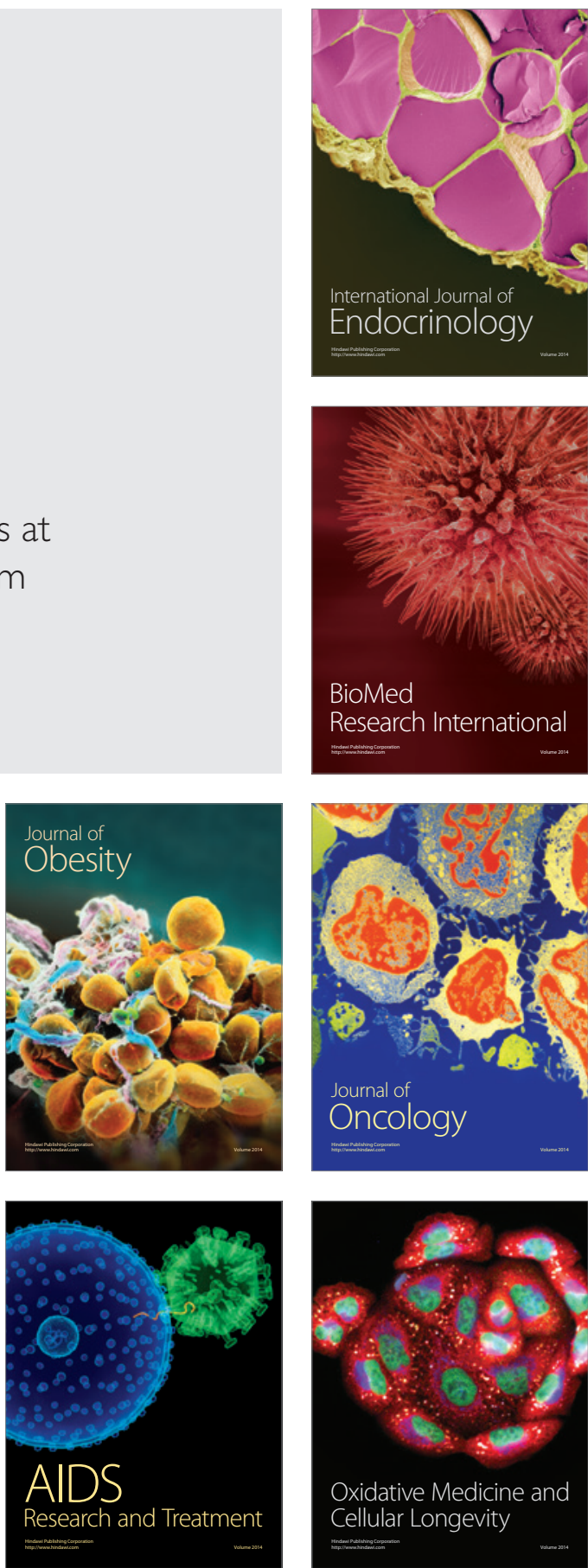